\title{
Cyclic excretion of urinary oestrogens in female tamarins (Saguinus oedipus)
}

J. A. French*†, D. H. Abbott $\ddagger$, G. Scheffler§, J. A. Robinson§ and R. W. Goy† $\S$

$\dagger$ Department of Psychology, University of Wisconsin, and $\S$ Wisconsin Regional Primate Research Center, Madison, Wisconsin 53706, U.S.A.; and

$\ddagger$ Department of Anatomy, University of Cambridge, Cambridge CB2 3DY, U.K.

\begin{abstract}
Summary. Urine was collected from 6 female cotton-top tamarins (Saguinus o. oedipus) and urinary oestrone and oestradiol concentrations were measured by radioimmunoassay. Oestrone was excreted at 50 -fold higher concentrations than oestradiol. Five females showed patterns of regular oestrone cyclicity, with a mean peak-to-peak oestrone cycle of $23.6 \pm 1.2$ days. Levels of oestradiol tended to vary with levels of oestrone excretion, but peaks were less pronounced and more variable. The sixth female, diagnosed as having 'wasting marmoset syndrome', had very low levels of excreted oestrogens, suggesting infertility. We suggest that urinary oestrone provides a good index to ovarian cyclicity in female cotton-top tamarins.
\end{abstract}

\section{Introduction}

Interest in the reproductive endocrinology of tamarins and marmosets (Primates: Family Callitrichidae) has increased in recent years, stimulated for a number of reasons. There is a growing recognition that the maintenance of populations of several callitrichid species (e.g. Saguinus o. oedipus, Leontopithecus rosalia) may be possible only through captive breeding programmes (Thorington, 1978), yet little is known about the basic reproductive biology of these species.

A persistent problem in callitrichid reproduction research is the lack of clear, reliable markers of ovarian cyclicity in females. Changes in vaginal cytology and peroxidase activity in common marmosets (Callithrix jacchus) are not correlated with a female's sexual state (Hearn \& Lunn, 1975). No menstrual bleeding has been reported nor are there obvious cyclic changes in the perigenital skin (Hampton, Hampton \& Landwehr, 1966; Brand, 1981). Finally, there is no well-defined behavioural oestrus in marmosets and tamarins; sexual activity is distributed across many reproductive conditions, including pregnancy and lactation (Hearn \& Lunn, 1975; Rothe, 1975). In this study, we monitored ovarian cyclicity in the female cotton-top tamarin by measuring excreted urinary oestrogens.

\section{Materials and Methods}

\section{Animals}

Six captive-born adult female cotton-top tamarins (Saguinus oedipus oedipus) were used. All were housed in large home cages (minimum dimensions $2.0 \times 1.0 \times 2.0 \mathrm{~m}$ ) with an adult male

\footnotetext{
* Present address: Department of Psychology, University of Nebraska, Omaha, Nebraska 68182, U.S.A.
} 
cotton-top tamarin. The mean age of females during the period of sampling was 3.8 years (range 1.8 to 8.0 years). Full-spectrum artificial lighting (Chroma-75, General electric, Inc.) was provided from $07: 00$ to 19:00 h. Additional details of housing and maintenance are provided by French \& Snowdon (1981).

\section{Urine collections}

Urine samples from females were collected approximately three times per week starting at 13:00-15:00 h. At least 1 day and no more than 3 days elapsed between successive urine collections. Females were removed from their home cage and placed in a metabolism cage $(20 \times 20$ $\times 25 \mathrm{~cm}$ ) with a wire mesh floor and a sloping funnel collector. Volumes of urine from 0.5 to $5.0 \mathrm{ml}$ were usually voided within 15 min after females were placed in metabolism cages; no female spent more than $30 \mathrm{~min}$ in a metabolism cage. Following collection, urine samples were centrifuged at $700 \mathrm{~g}$ for $5 \mathrm{~min}$ to eliminate faecal matter and other contaminants. A $0.3 \mathrm{ml}$ sample was removed for creatinine determination and the remainder was kept for steroid assay. All samples were then frozen and kept at $-20^{\circ} \mathrm{C}$ until assayed.

\section{Oestrogen assays}

Duplicate aliquants $(2-5 \mu 1)$ of each urine sample were placed in $1.0 \mathrm{ml}$ phosphate-buffered saline (pH 5.0). Samples were hydrolysed by the addition of $20 \mu \mathrm{l} \beta$-glucuronidase (Type H-2, Crude Solution; Sigma Chemical, St Louis, Missouri), and this mixture was incubated overnight at $37^{\circ} \mathrm{C}$. The efficiency of the hydrolysis procedure was assessed by the recovery, after diethyl ether extraction, of $45 \mathrm{pg}\left[6,7(\mathrm{~N}) \cdot{ }^{-} \mathrm{H}\right]$ oestrone sulphate (sp. act. $53 \mathrm{Ci} / \mathrm{mmol}$ : New England Nuclear, Boston, Massachusetts) and $34.5 \mathrm{pg}\left[6,7(\mathrm{~N}){ }^{-3} \mathrm{H}\right]$ oestradiol glucuronide (sp. act. $51 \mathrm{Ci} / \mathrm{mmol}$ : New England Nuclear). Recovery of $\left[{ }^{3} \mathrm{H}\right]$ oestrone was $94 \cdot 0 \pm 2 \cdot 6 \%$ (mean \pm s.e.m. throughout, except where noted) after hydrolysis and extraction, and $3 \cdot 2 \pm 0 \cdot 2 \%$ after extraction only. Recovery of $\left[{ }^{3} \mathrm{H}\right]$ oestradiol was $100 \cdot 3 \pm 1.2 \%$ after hydrolysis and extraction and $42.6 \pm 1.7 \%$ after extraction alone. Oestrogens were extracted with $5.0 \mathrm{ml}$ freshly opened diethyl ether (A.R., Mallinckrodt). The extracts were evaporated and reconstituted in $0.15 \mathrm{ml}$ dichloromethane : methanol $(98: 2, \mathrm{v} / \mathrm{v})$.

Oestrone and oestradiol separation was accomplished on 0.8 g Sephadex LH-20 (Pharmacia Fine Chemicals, Piscataway, New Jersey) $10 \mathrm{~mm}$ diameter glass columns. A dichloromethane:methanol $(98: 2, \mathrm{v} / \mathrm{v})$ solvent system resulted in the following elution pattern: $0-4 \mathrm{ml}$ discard; 5-7 ml inclusive, oestrone; 8 and $9 \mathrm{ml}$ discard; 10-16 ml inclusive, oestradiol. Both oestrogen fractions were evaporated, and the oestrone fraction was diluted with $5.0 \mathrm{ml}$ ethanol. Aliquants of $0.2 \mathrm{ml}$ diluted oestrone $(1 / 1000)$ were placed in assay tubes, evaporated, and used in the assay. Procedural losses during extraction and chromatography were estimated initially by the recovery of trace amounts $\left(1000\right.$ c.p.m.) of $\left[2,4,6,7(\mathrm{~N})-{ }^{3} \mathrm{H}\right]$ oestrone or $\left[2,4,6,7(\mathrm{~N})-{ }^{3} \mathrm{H}\right]$ oestradiol that had been added to each sample, and later by the recovery of similar trace amounts of labelled steroids extracted from phosphate buffer and run through the column system. Internal recovery of labelled steroid from each sample was $85.8 \pm 0.8 \%$ for oestrone $(n=26)$ and $76.0 \pm 0.4 \%$ for oestradiol $(n=68)$. External recovery of labelled steroids from buffer alone yielded values of 81.9 $\pm 1.0 \%$ and $81.6 \pm 1.5 \%$ for oestrone and oestradiol, respectively $(n=14)$. These values were not markedly different from those obtained by internal recovery. External recovery values were used to correct sample values for procedural losses.

Oestrone assay tubes contained the extracted sample, $0.1 \mathrm{ml}\left[2,4,6,7(\mathrm{~N})-{ }^{-3} \mathrm{H}\right]$ oestrone $(2.8 \mathrm{pg}$, 7500 c.p.m.; sp. act. $95.3 \mathrm{Ci} / \mathrm{mmol}$ : New England Nuclear), and $0.1 \mathrm{ml}$ oestrone antiserum. The oestrone antiserum (Miles Biologicals, Inc., Elkhart, Indiana) was diluted so that approximately $50 \%$ of the tritiated oestrone was bound in the absence of unlabelled steroid. Cross-reactivity with the oestrone antiserum was $<0.1 \%$ for oestradiol and $<0.01 \%$ for oestriol, progesterone, testosterone and dihydrotestosterone. Oestradiol assay tubes contained extracted sample, $0 \cdot 1 \mathrm{ml}$ 
$\left[2,4,6,7(\mathrm{~N}){ }^{-3} \mathrm{H}\right]$ oestradiol $(2 \cdot 4$ pg, 7500 c.p.m.; sp. act. $113 \cdot 0 \mathrm{Ci} / \mathrm{mmol}:$ New England Nuclear $)$ and $0.1 \mathrm{ml}$ oestradiol antiserum. The antiserum (Holly Hill Biologicals, Inc., Hillsboro, Oregon) was diluted so that approximately $50 \%$ of the tritiated oestradiol was bound in the absence of unlabelled steroid. Cross-reactivity with the oestradiol antiserum was $5.8 \%$ for oestrone, $0.3 \%$ for oestriol, $0.82 \%$ for testosterone, and $0.07 \%$ for progesterone. For both steroids, a triplicate standard curve (dose range 5-150 pg) was included for each set of samples (50-60 samples in duplicate).

After incubation of the sample, antiserum, and tracer at $4^{\circ} \mathrm{C}$ for $15-18 \mathrm{~h}$, separation of free from bound steroid was accomplished by the addition of $1.0 \mathrm{ml}$ dextran-coated charcoal $(0.25 \% \mathrm{w} / \mathrm{v}$ Norit A activated charcoal and $0.025 \%$ w/v Dextran T-70 in phosphate-buffered saline, pH 7.0). After mixing, incubation for $15 \mathrm{~min}$, and centrifugation for $12 \mathrm{~min}$ at $1200 \mathrm{~g}$, the supernatant containing the bound steroid was poured into vials and $10 \mathrm{ml}$ scintillation cocktail $(66 \% \mathrm{v} / \mathrm{v}$ toluene; $34 \% \mathrm{v} / \mathrm{v}$ Triton X, Research Products, Inc., Elk Grove Village, Illinois; and $0.3 \% \mathrm{w} / \mathrm{v}$ Omni-fluor, New England Nuclear) were added. Each tube was counted in a scintillation counter for $10 \mathrm{~min}$ or up to 10000 counts.

Buffer blank values for oestrone and oestradiol were $2.24 \pm 1.64$ (s.d.) pg and $1.08 \pm 1.42$ (s.d.) $\mathrm{pg}$, respectively $(n=14)$. Assay sensitivity for oestrone and oestradiol was then set at $5.5 \mathrm{pg}$ and $3.92 \mathrm{pg}$, respectively. Intra-assay variation, expressed as a coefficient of variation, was calculated on the basis of duplicate sample agreement according to the method of van der Molen (1970) and was $9.4 \%$ for oestrone and $6.7 \%$ for oestradiol. A urine pool from adult female tamarins was assayed in triplicate with each set of unknowns. Interassay variability based on these samples was $10 \cdot 1 \%$ for oestrone and $14.7 \%$ for oestradiol $(n=8)$.

\section{Creatinine assay}

To control for variable fluid intake and output, hormone concentrations were corrected for the creatinine concentration of each sample (Klopper, 1976). Creatinine concentration was measured in duplicate by a modified Jaffe reaction end-point assay (Tietz, 1976). Urine $(0.1 \mathrm{ml})$ was placed in optical cuvettes and then diluted to $4.0 \mathrm{ml}$ with distilled water. Picric acid $(0.04 \mathrm{M}, 1 \mathrm{ml})$ and $1.0 \mathrm{ml}$ $\mathrm{NaOH}(0.75 \mathrm{M})$ were added, the contents mixed, and the absorbance at $500 \mathrm{~nm}$ read 15 min later on a colorimeter. Intra-assay variability was measured by repeated assays of a single pool at two concentrations and was $4.6 \%(n=16)$. Inter-assay variability was monitored by the repeated assay of a tamarin urine pool in successive assays and was $5 \cdot 1 \%(n=10)$.

\section{Validation of oestrogen assays}

The biological validity of the oestrogen assays was assessed by assaying in triplicate serial dilutions of tamarin urine from animals in a variety of reproductive states. The slopes of the resulting binding inhibition curves were then compared with the slope of the standard curve.

Labelled steroid binding inhibition curves for oestrone and oestradiol are shown in Text-figs l(a) \& (b). For all samples, increasing volumes of urine resulted in a displacement curve similar to that of the standard curve. Slope tests (Steel \& Torrie, 1960) revealed that none of the slopes for serial dilutions of urine were significantly different from the slope of the standard curve. Spearman correlation coefficients for volume of urine added and percentage of labelled steroid bound to the antiserum were -0.97 to -1.00 , showing that assay estimation was not affected by varying the volume of urine assayed. Urine from a 2-month-old infant female tamarin was assayed at volumes 40 times greater than that used for adult females (oestrone, $8.0 \mu \mathrm{l}$; oestradiol, $200 \mu \mathrm{l}$ ). Oestrone was undetectable in infant female urine using this volume $(<5.5 \mathrm{pg}$ in $8 \mu \mathrm{l})$, and oestradiol levels were just above the limit of detectability $(6 \cdot 27 \mathrm{pg}$ in $200 \mu \mathrm{l})$.

Oestrone was excreted at much higher concentrations than oestradiol in the urine of female tamarins. Of the total immunoreactive oestrogen measured, $97.8 \%$ was oestrone and $2 \cdot 2 \%$ was oestradiol. The oestrone/oestradiol ratio was consistent for individual females $(46 \cdot 7 \pm 7 \cdot 8$; mean \pm s.e.m.). 


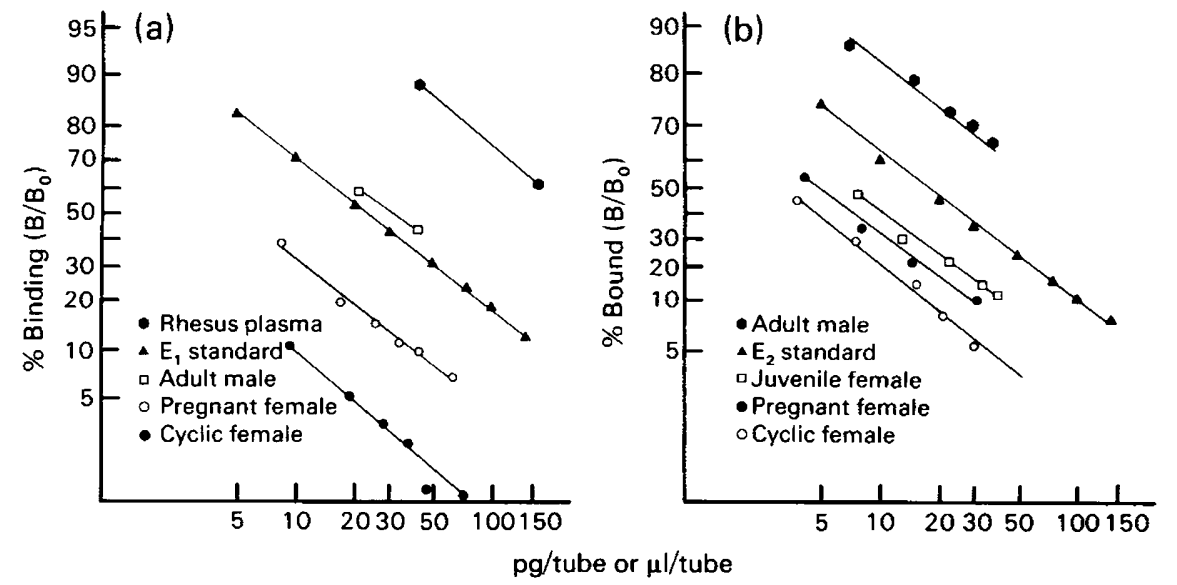

Text-fig. 1. Displacement of $\left[{ }^{3} \mathrm{H}\right]$ oestrone (a) and $\left[{ }^{3} \mathrm{H}\right]$ oestradiol (b) from antisera by increasing doses of standards and serial dilutions of tamarin urine samples, expressed as percentage of total bound $\left(B / B_{0}\right)$.

\section{Determination of ovarian cyclicity}

Cyclicity was determined with reference to peaks in oestrone excretion. A peak was defined as an elevated concentration of oestrone which was neither preceded nor followed by a higher oestrogen concentration for at least 4 consecutive samples.

\section{Results}

Five of the 6 females studied showed periods of regular cycles in oestrogen excretion (Text-fig. 2). Oestrone peaks were easily identifiable, but oestradiol peaks were less pronounced and more variable. The oestrone cycle was characterized by a nadir 10 days before the oestrone peak $(3.83 \pm$ $0.63 \mu \mathrm{g} / \mathrm{mg}$ creatinine), followed by a gradual increase in oestrone excretion during the 8 days

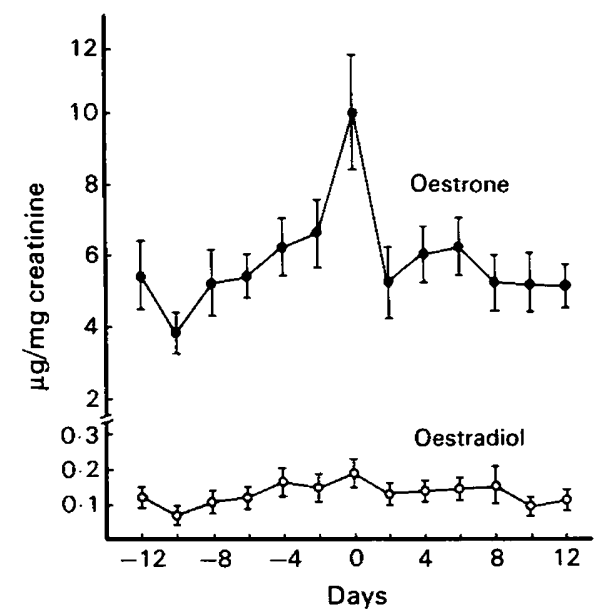

Text-fig. 2. Mean ( \pm s.e.m.) values of excreted oestrone and oestradiol across cycles in female tamarins. The data are a composite based on 22 oestrone peaks from 5 females. Cycles are normalized to the day of the oestrone peak (Day 0 ). 
Table 1. Peak and nadir concentrations $(\mu \mathrm{g} / \mathrm{mg}$ creatinine) and cycle length in tamarins

\begin{tabular}{|c|c|c|c|c|c|c|}
\hline \multirow[b]{2}{*}{ Female } & \multirow{2}{*}{$\begin{array}{l}\text { No. of } \\
\text { cycles }\end{array}$} & \multicolumn{2}{|c|}{ Oestrone } & \multicolumn{2}{|c|}{ Oestradiol } & \multirow{2}{*}{$\begin{array}{l}\text { Cycle length } \\
\text { (days) }\end{array}$} \\
\hline & & Peak & Nadir & Peak & Nadir & \\
\hline $\mathrm{Va}$ & 2 & $5.91 \pm 0.04$ & $3.59 \pm 0.18$ & $0.132 \pm 0.016$ & $0.063 \pm 0.003$ & 21 \\
\hline $\mathrm{Rn}$ & 4 & $19.36 \pm 5.96$ & $8.87 \pm 0.67$ & $0.236 \pm 0.088$ & $0.126 \pm 0.008$ & $18.5 \pm 0.5$ \\
\hline Yv & 5 & $4.39 \pm 0.27$ & $2.52 \pm 0.04$ & $0.090 \pm 0.015$ & $0.063 \pm 0.007$ & $23.3 \pm 0.3$ \\
\hline $\mathbf{M a}$ & 5 & $7.81 \pm 1.25$ & $4.37+0.83$ & $0.091 \pm 0.021$ & $0.059 \pm 0.009$ & $27 \cdot 3 \pm 2 \cdot 3$ \\
\hline $\mathrm{Ca}$ & 6 & $11.68 \pm 0.79$ & $2.94 \pm 0.73$ & $0.302 \pm 0.025$ & $0.076 \pm 0.026$ & $24.5 \pm 2.6$ \\
\hline
\end{tabular}

Values are mean \pm s.e.m.

preceding the sharp peak in oestrone at Day $0(10.01 \pm 1.51 \mu \mathrm{g} / \mathrm{mg} \mathrm{Cr})$. Following this peak, levels of excreted oestrone returned rapidly to basal levels, showed a brief rise, and then a gradual decline to basal levels $8-12$ days after the peak.

The mean peak-to-peak interval was $23.6 \pm 1.2$ days, and the median and modal cycle length was 23 days (range 18-31 days; see Table 1 for values for individual females). Changes in oestradiol levels tended to correspond to changes in oestrone levels across the cycle $\left(r_{\mathrm{s}}=0.80\right)$, although the variability in oestradiol excretion between females and across cycles within an individual female was high.

Concentrations of oestrone excreted were also variable across females, with mean peak values for individuals ranging from 19.36 to $4.39 \mu \mathrm{g} / \mathrm{mg}$ creatinine and nadir values ranging from 8.87 to $2.52 \mu \mathrm{g} / \mathrm{mg}$ creatinine. However, females with high nadir values tended to have correspondingly high peak values (Table 1). Typical oestrogen cycles for 3 females are shown in Text-fig. 3(a-c).

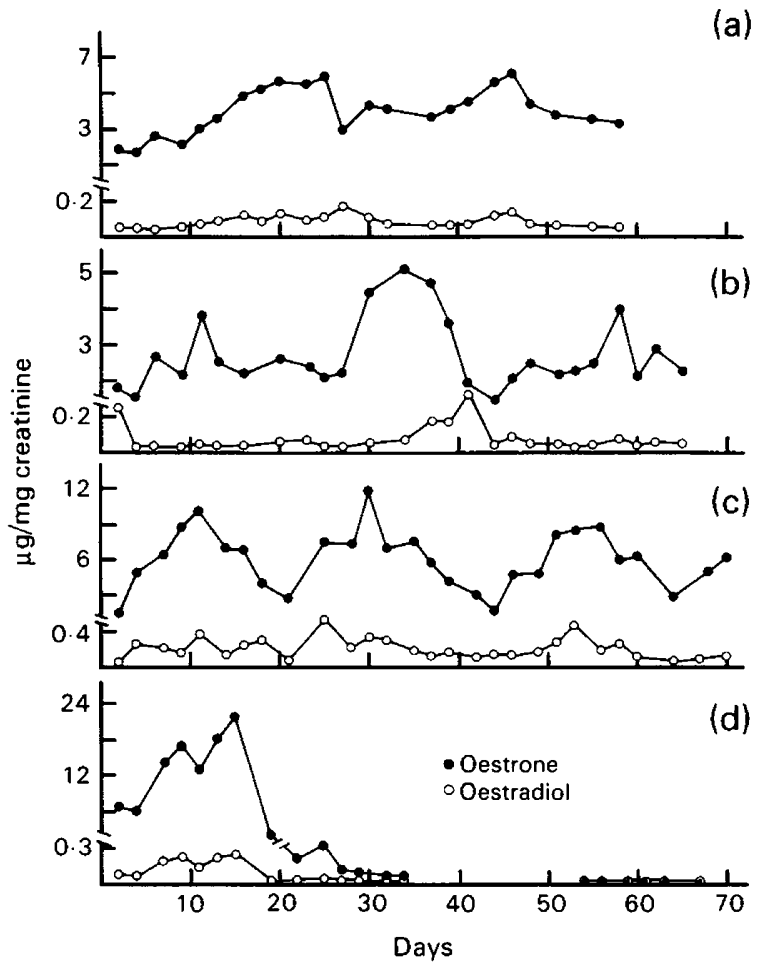

Text-fig. 3. Representative oestrogen cycles in 3 females (a-c). Female Ru (d) was diagnosed as having 'wasting marmoset syndrome' on Day 24. 
The sixth female $(\mathrm{Ru})$ initially showed evidence of ovarian cyclicity (Text-fig. 3d) followed by a rapid and sustained reduction in oestrogen excretion 18-20 days after the onset of sampling for this study. On Day 35, the female was eliminated from the sampling schedule and treated for a cluster of symptoms known as 'wasting marmoset syndrome' (King, 1976). Although the symptoms improved only slightly, urine collections were resumed on Day 54 for 13 days. Levels of excreted oestrone and oestradiol remained low during this time.

\section{Discussion}

This paper: (1) describes a valid assay for tamarin urinary oestrogens, (2) indicates that oestrone is excreted in the urine at 50 -fold higher concentrations than oestradiol by cyclic adult female cottontop tamarins, (3) reveals that patterns of oestrone excretion are cyclic with an approximately 23-day periodicity, and (4) suggests that reduced oestrogen excretion may be associated with 'wasting marmoset syndrome'.

Preslock, Hampton \& Hampton (1973) studied endocrine cycles in female cotton-top tamarins by measuring plasma oestrogens and progestagens: there was a $15.5 \pm 1.5$ day interval between successive progestagen peaks, substantially shorter than the oestrone cycles reported in this paper. More recently, Brand (1981) has documented urinary oestrogen cycles of $22.7 \pm 1.7$ days in female cotton-top tamarins, which is in good agreement with the $23.6 \pm 1.2$ day oestrone cycles reported here. In Brand's study (1981), an antiserum raised against an oestradiol-17 $\beta$-antigen complex was used. Given the high degree of cross-reactivity of that antibody with oestrone $(>25 \%)$ and the much higher concentrations of oestrone versus oestradiol in the urine of female tamarins reported here, it is probable that the cycles reported by Brand (1981) were primarily due to variations in oestrone excretion. A summary of the information currently available on reproductive cycles in tamarins and marmosets is presented in Table 2. Like other New World primates (e.g. capuchins, Cebus apella: Nagle et al., 1979; squirrel monkeys, Saimiri sciureus: Wolf, O'Connor \& Robinson, 1977; owl monkeys, Aotus trivirgatus: Bonney, Dixson \& Fleming, 1980), ovarian cycles in callitrichids are shorter than ovarian cycles in Old World primates and hominoids (e.g. rhesus

Table 2. Reproductive cycles in tamarins and marmosets (Primates: Family Callitrichidae)

\begin{tabular}{|c|c|c|c|}
\hline Species & Measure & Cycle length (days) & Reference \\
\hline \multirow[t]{4}{*}{$\begin{array}{l}\text { Cotton-top tamarin } \\
\quad \text { (Saguinus o. oedipus) }\end{array}$} & $\begin{array}{l}\text { Urinary oestrone and } \\
\text { oestradiol }\end{array}$ & $23 \cdot 6 \pm 1 \cdot 2$ & Present study \\
\hline & Urinary oestrogens & $22.7 \pm 1.7$ & Brand (1981) \\
\hline & $\begin{array}{c}\text { Leucocyte alkaline } \\
\text { phosphatase }\end{array}$ & $13 \cdot 2 \pm 1 \cdot 6$ & Hampton \& Hampton (1978) \\
\hline & $\begin{array}{l}\text { Plasma oestrogens and } \\
\text { progestagens }\end{array}$ & $15 \cdot 5 \pm 1 \cdot 5$ & Preslock et al. (1973) \\
\hline \multirow[t]{2}{*}{$\begin{array}{l}\text { Saddleback tamarin } \\
\text { (Saguimus fuscicollis) }\end{array}$} & $\begin{array}{l}\text { Urinary oestrogens } \\
\text { Urinary oestrogens and } \mathbf{L H}\end{array}$ & $17 \cdot 7 \pm 3 \cdot 2$ & $\begin{array}{l}\text { Katz \& Epple (1979) } \\
\text { Hodges et al. (1981) }\end{array}$ \\
\hline & $\begin{array}{l}\text { Leucocyte alkaline } \\
\text { phosphatase }\end{array}$ & $14 \cdot 6 \pm 1 \cdot 6$ & Hampton \& Hampton (1978) \\
\hline \multirow[t]{2}{*}{$\begin{array}{l}\text { Common marmoset } \\
\text { (Callithrix jacchus })\end{array}$} & $\begin{array}{l}\text { Plasma oestradiol, } \\
\text { progesterone and } \mathrm{LH}\end{array}$ & $16 \cdot 4 \pm 1 \cdot 7$ & Hearn \& Lunn (1975) \\
\hline & Urinary oestrogens & 21 & Lunn (1978) \\
\hline $\begin{array}{l}\text { Lion tamarin } \\
\quad \text { (Leontopithecus rosalia) }\end{array}$ & Sexual activity & $|4-2|$ & Kleiman (1978) \\
\hline
\end{tabular}


monkeys, Macaca mulatta: Knobil, 1974; lowland gorillas, Gorilla gorilla gorilla: Nadler, Graham, Collins \& Gould, 1979).

The estimates of ovarian cycle length in the cotton-top tamarin based on urinary oestrogen measures are 7-8 days longer than estimates relying on plasma hormone concentrations (Table 2). Similarly, there are varying estimates of the ovarian cycle length in common marmosets, with a longer cycle length documented when urinary oestrogens are the primary measure. However, Hearn (1982) has reported a 26-28-day plasma progesterone cycle in common marmosets. Brand (1981) has suggested that the stress associated with capture and blood sampling may disrupt, possibly shorten, the cycle in female cotton-top tamarins. However, in the present study females were captured three times weekly for urine sampling and the estimates of the urinary oestrogen cycle reported here are in agreement with those of Brand (1981). Blood and urine samples collected on the same day provided virtually identical information regarding ovarian cyclicity in the owl monkey (Bonney et al., 1979). This latter finding points to the need for (i) concurrent blood and urine sampling to verify the cycle length in tamarins and (ii) an estimate of progesterone concentrations to distinguish ovulatory from anovulatory cycles. The latter studies are currently in progress.

Oestrone was excreted in much higher concentrations than oestradiol in the urine of female tamarins. This is in apparent contrast to the common marmoset, in which oestradiol is the major urinary oestrogen in both pregnant and non-pregnant females (Shackleton, 1974, 1975; Lunn, 1978). Oestrone is also the major urinary oestrogen excreted in the cyclic adult female owl monkey (Bonney \& Setchell, 1980), vervet monkey (Cercopithecus aethiops: Setchell, Bull \& Adlercreutz, 1980), hanuman langur (Presbytis entellus entellus: Shandilya, Ramaswami \& Shandilya, 1976), orang-utan (Pongo pygmaeus: Collins, Graham \& Preedy, 1975), and chimpanzee (Pan troglodytes: Graham, Collins, Robinson \& Preedy, 1972). Whether the higher concentrations of urinary oestrone in tamarins reflects higher circulating levels of oestrone or whether the majority of the circulating oestradiol is metabolized to oestrone in the liver or kidney before excretion (Diczfalusy \& Levitz, 1970) is unclear. A preliminary report of 100-fold higher oestrone over oestradiol concentration in the plasma of adult female saddleback tamarins (Katz \& Epple, 1980) indicates that the former explanation may be more likely.

Female Ru initially showed normal concentrations of urinary oestrogen excretion, but steroid excretion dropped precipitously around Day 18 and remained low throughout Days 35 and 54-67 of the urine collection series (Text-fig. 3d). This animal was diagnosed as having 'wasting marmoset syndrome' (WMS), a cluster of symptoms that includes general debilitation, weight and hair loss, listlessness, and chronic diarrhoea (King, 1976). This syndrome often results in the death of the afflicted animal. Not surprisingly, a drastic reduction in ovarian functioning can apparently be added to the cluster of symptoms, as levels of excreted oestrone and oestradiol were low or undetectable in female Ru after the onset of WMS. Loss of fertility may precede other more visible signs of WMS since the excretion of oestrogens was reduced 15 days before the decision to isolate this female and initiate medical treatment of the symptoms.

This study supports the findings of Brand (1981) that female cotton-top tamarins exhibit 22-23day cycles in oestrogen excretion. It further demonstrates that oestrogens are excreted predominantly in the form of oestrone, with much lower concentrations of oestradiol being present. The RIA validation of oestrogens in urine samples as well as the demonstration of cyclic ovarian functioning in adult females provide a reference point for future studies on the behavioural correlates of ovarian cyclicity and the effects of the social environment on fertility in female tamarins.

We thank A. Eglash and K. Zirbel for assistance with urine collections; C. Brazy, S. Londregan and R. Sweigard for help with hormone determinations; and C. T. Snowdon and N. S. Lieberman for helpful comments on earlier versions of the manuscript. The work was supported by funds from the U. W. Graduate School, by P.H.S. MH 29,775 to C.T.S., by MH 21,312 to R.W.G., and by NIH RR00167 to the Wisconsin Regional Primate Research Center. This is publication 22-001 of the WRPRC. 


\section{References}

Bonney, R.C. \& Setchell, K.D.R. (1980) The excretion of gonadal steroids during the reproductive cycle of the owl monkey (Aotus trivirgatus). J. Steroid Biochem. $12,417-422$.

Bonney, R.C., Dixson, A.F. \& Fleming, D. (1979) Cyclic changes in the circulating and urinary levels of ovarian steroids in the adult female owl monkey (Aotus trivirgatus). J. Reprod. Fert. 56, 271-280.

Bonney, R.C., Dixson, A.F. \& Fleming, D. (1980) Plasma concentrations of oestradiol- $17 \beta$, oestrone, progesterone and testosterone during the ovarian cycle of the owl monkey (Aotus trivirgatus). J. Reprod. Fert. 60, 101-107.

Brand, H.M. (1981) Urinary oestrogen excretion in the female cotton-topped tamarin (Saguinus oedipus oedipus). J. Reprod. Fert. 62, 467-473.

Collins, D.C., Graham, C.E. \& Preedy, J.R.K. (1975) Identification and measurement of urinary estrone, estradiol-17\%, estriol, and pregnandiol and androsterone during the menstrual cycle of the orangutan. Endocrinology 96, 93-101.

Diczfalusy, E. \& Levitz, M. (1970) Formation, metabolism, and transportation of estrogen conjugates. In Chemical and Biological Aspects of Steroid Conjugation, pp. 291-320. Eds S. Bernstein \& S. Solomon. Springer-Verlag, New York.

French, J.A. \& Snowdon, C.T. (1981) Sexual dimorphism in response to unfamiliar intruders in the tamarin, Saguinus oedipus. Anim. Behav. 29, 822-829.

Graham, C.E., Collins, D.C., Robinson, H. \& Preedy, J.R.K. (1972) Urinary levels of estrogens and pregnanediol and plasma levels of progesterone during the menstrual cycle of the chimpanzee: relationship to the sexual swelling. Endocrinology 91, 13-24.

Hampton, J.K., Hampton, S.H. \& Landwehr, B.T. (1966) Observations on a successful breeding colony of the marmoset, Oedipomidas oedipus. Folia primat. 4, 265287.

Hampton, S.H. \& Hampton, J.K. (1978) Detection of reproductive cycles and pregnancy in tamarins (Saguinus spp.). In The Biology and Conservation of the Callitrichidae, pp. 173-180. Ed. D. G. Kleiman. Smithsonian Press, Washington, D.C.

Hearn, J.P. (1982) The marmoset monkey in reproductive research. Int. J. Primat. 3, p. 242, Abstr. 7.

Hearn, J.P. \& Lumn, S.F. (1975) The reproductive biology of the marmoset monkey, Callithrix jacchus. In Breeding Simians for Developmental Biology (Lab. Anim. Handbook No. 6), pp. 191-202. Eds F. T. Perkins \& P. N. O'Donoghue. Laboratory Animals Ltd, London.

Hodges, J.K., Gulick, B.A., Czekala, N.M. \& Lasley, B.L. (1981) Comparison of urinary oestrogen excretion in South American primates. J. Reprod. Fert. 61, 83-90.

Katz, Y. \& Epple, G. (1979) The coming of age in female Saguinus (marmoset monkeys). Endocrinology 104A, p. 259 , Abstr. 743.

Katz, Y. \& Epple, G. (1980) The ontogeny of plasma steroids in marmoset monkeys (Saguinus). Biol. Reprod. 24, Suppl. p. 132A, Abstr. 219.

King, G. (1976) An investigation into "wasting marmoset syndrome" at Jersey Zoo. Dodo 13, 97-107.

Kleiman, D.G. (1978) Characteristics of reproduction and sociosexual interactions in pairs of lion tamarins (Leontopithecus rosalia) during the reproductive cycle. In The Biology and Conservation of the Callitrichidae, pp. 181-190. Ed. D. G. Kleiman. Smithsonian Press, Washington, D.C.

Klopper, A. (1976) The choice between assays on blood or on urine. In Hormone Assays and Their Clinical Applications, pp. 73-86. Eds J. A. Loraine \& E. T. Bell. Churchill Livingstone, Edinburgh.

Knobil, E. (1974) On the control of gonadotrophin secretion in the rhesus monkey. Recent Prog. Horm. Res. 30, 1-46.

Lunn, S.F. (1978) Urinary oestrogen excretion in the common marmoset, Callithrix jacchus. In Biology and Behaviour of Marmosets, pp. 67-74. Eds H. Rothe, H.-J. Wolters \& J. P. Hearn. Eigenverlag-H. Rothe, Gottingen.

Nadler, R.D., Graham, C.E., Collins, D.C. \& Gould, K.G. (1979) Plasma gonadotropins, prolactin, gonadal steroids and genital swelling during the menstrual cycle of lowland gorillas. Endocrinology 105, 290-296.

Nagle, C.A., Denari, J.H., Quiroga, S., Riarte, A., Merlo, A., Germino, N.I., Gomez-Argana, F. \& Rosner, J.M. (1979) The plasma pattern of ovarian steroids during the menstrual cycle in capuchin monkeys (Cebus apella). Biol. Reprod. 21, 979.983.

Preslock, J.P., Hampton, S.H. \& Hampton, J.K. (1973) Cyclic variations of serum progestins and immunoreactive estrogens in marmosets. Endocrinology 92, 1096-1101.

Rothe, H. (1975) Some aspects of sexuality and reproduction in groups of captive marmosets (Callithrix jacchus). Z. Tierpsychol. 37, 255-273.

Setchell, K.D.R., Bull, R. \& Adlercreutz, H. (1980) Steroid excretion during the reproductive cycle and in pregnancy of the vervet monkey (Cercopithecus aethiops pygerythrus). J. Steroid Biochem. 12, 375-384.

Shackleton, C.H.L. (1974) Progesterone and oestrogen metabolism in the pregnant marmoset (Callithrix jacchus). J. Steroid Biochem. 5, 597-600.

Shackleton, C.H.L. (1975) Excretion of steroids by the adult marmoset monkey (Callithrix jacchus). J. Steroid Biochem. 6, 1429-1432.

Shandilya, L.N., Ramaswami, L.S. \& Shandilya, N. (1976) Oestrogen metabolites in urine during the menstrual cycle, pregnancy and puerperium in the Indian hanuman langur (Presbytis entellus entellus). J. Reprod. Fert. 47, 7-11.

Steel, R.G.D. \& Torrie, J.H. (1960) Principles and Procedures of Statistics. McGraw-Hill, New York.

Thorington, R.W. (1978) Conservation status of the Callitrichidae, Panel discussion. In The Biology and Conservation of the Callitrichidae, pp. 147-159. Ed. D. G. Kleiman. Smithsonian Press, Washington, D.C.

Tietz, N.W. (1976) Fundamentals of Clinical Chemistry. W. B. Saunders, Philadelphia.

van der Molen, H.J. (1970) Estimation of androstenedione and testosterone by physico-chemical methods. In The Androgens of the Testis, p. 148. Ed. K. B. EikNes. Marcel Dekker, New York.

Wolf, R.C., O'Connor, R.F. \& Robinson, J.A. (1977) Cyclic changes in plasma progestins and estrogens in squirrel monkeys. Biol. Reprod. 17, 228-231. 